\title{
ANALISIS EFEKTIVITAS PENERAPAN SISTEM AKUNTANSI KEUANGAN DAERAH PADA DINAS PENDAPATAN PENGOLAAN KEUANGAN DAN ASET DAERAH (DPPKAD) KOTA TANJUNGPINANG
}

\author{
Masyitah As Sahara \\ (Dosen STIE Pembangunan Tanjungpinang) \\ masyitah@stie-pembangunan.ac.id
}

\begin{abstract}
Abstrak: Sistem Keuangan Daerah merupakan sistem yang harus dijalankan dan diterapkan oleh setiap pemerintahan daerah khususnya. Dengan dikeluarkannya Peraturan Pemerintah Nomor 105 Tahun 2000 tentang Laporan Pertanggungjawaban Keuangan Daerah, maka pemerintah daerah wajib melaporkan laporan keuanganya sesuai dengan ketentuan yang terdapat pada PP No.105 Tahun 2000. Pengujian yang dlakukan untuk menganalisis efektivitas sistem akuntansi yang digunakan, menggunakan alat instrument yaitu; kuesioner, dimana daftar pertanyaan dibagi kedalam 5 (lima) aspek yaitu :Hardware, Software, Procedure, Information dan Brainware.

Kata Kunci: $\quad$ Sistem Akuntansi Laporan Aliran Kas, Neraca, Catatan Atas Laporan Keuangan, dan Laporan Realisasi Anggaran.
\end{abstract}

\section{PENDAHULUAN}

Akuntansi dilaksanakan baik dalam perusahaan yang bertujuan mencari laba maupun dalam oraganisasi - organisasi yang tidak mencari laba.Instansi pemerintah membutuhkan akuntansi, karena selain sebagai lembaga politik, instansi pemerintahan juga memiliki aspek sebagai lembaga ekonomi.Sebagai lembaga ekonomi, pemerintahan melakukan berbagai bentuk pengeluaran guna membiayai kegiatankegiatan yang dilakukannya.Untuk itu instansi harus melakukan berbagai upaya untuk memperoleh penghasilan guna menutupi biaya-biaya tersebut.

Berdasarkan fenomena diatas, maka penulis tertarik untuk melakukan penelitian denga mengambil judul "ANALISIS EFEKTIVITAS PENERAPAN SISTEM AKUNTANSI KEUANGAN DAERAH PADA DINAS PENDAPATAN PENGELOLAAN KEUANGAN DAN ASET DAERAH (DPPKAD) KOTA TANJUNGPINANG"

\section{Tujuan Penelitian}

1) Untuk mengetahui efektif tidaknya suatu sistem akuntansi yang digunakan dilihat dari segi hardware. 2) untuk mengetahui efektivitas penggunaan software dalam menjalankan sistem akuntansi. 3) dari segi brainware, untuk dapat memahami dan menjalankan konsepkonsep sistem akuntansi. 4) untuk mengetahui keakuratan informasi yang dihasilkan oleh sistem akuntansi. 5) untuk dapat memahami prosedur-prosedur dalam sistem akuntansi keuangan.

\section{Manfaat Peneitian}

Manfaat dari penelitian ini adalah a) Bagi peneliti, agar dapat menambah pengetahuan bagi penelitian dibidang akuntansi pemerintahan. b) Bagi pembaca, agar dapat menjadi sumber informasi baru berkenaan dengan akuntansi pemerintahan serta dapat menambah wawasan pembaca.

\section{METODE PENELITIAN \\ Definisi Operasional}

a) Sistem Akuntansi Pemerintahan, sebagai sistem yang mengelola semua transaksi keuangan. b) Sistem Akuntansi Manual, yang terdiri atas dokumen bukti transaksi, alat pencatatan, dan prosedur yang digunakan perusahaan untuk mencatat transaksi-transaksi. c) Sistem Akuntansi Double Entry, dalam sistem ini setiap transaksi dicatat pada dua sisi sekaligus yaitu debit dan kredit. d) Sistem Akuntansi Single Entry, pencatatan dilakukan hanya terhadap transaksi yang mempengaruhi kas. e) Sistem Akuntansi Komputer, rancangan yang menggunakan komputer untuk mempermudah proses akuntansi.

\section{Pengukuran Variabel}

Penelitian menggunakan 2 variabel yaitu: a) Variabel Independen ( $\mathrm{x}$ ), yaitu sistem akuntansi sebelum dilaksanakannya Sistem 
Akuntansi Keuangan Daerah (SAKD), dalam hal ini menggunakan rumus :

$$
X=\frac{\sum X i \mathrm{i}=1}{n}
$$

Keterangan :

$\mathrm{Xi}$ : Penilaian komponen sebelum dilakukannya SAKD.

$\mathrm{n}$ : Jumlah responden.

b) Variabel Dependen (y), yaitu sistem akunansi setelah dilaksanakannya Sistem Akuntansi Keuangan Daerah (SAKD), untuk variable dependen dapat menggunakan rumus sebagai berikut :

$$
\mathrm{X}=\frac{\sum \mathrm{Yi} \mathrm{i}=1}{\mathrm{n}}
$$

Keterangan:

Yi : Penilaian komponen sesudah dilakukannya SAKD.

n : Jumlah Responden.

\section{Jenis Data}

Dalam rangka penelitian ini, data dan informasi yang digunakan adalah data primer dan sekunder : a) Data Primer, diperolaeh dari penyebaran kuesioner dan wawancara. b) Data Sekunder, diperoleh dari buku-buku, laporanlaporan dan peraturan perundang-undangan.

\section{Sumber Data}

Data yang digunakan dalam penelitan ini adalah hasil wawancara dan penyebaran kuesioner yang dilakukan dengan cara mengumpulkan data dengan menanyakan pokok-pokok masalah secara lebih terperinci. Pertanyaan kuesioner yang disebarkan terdiri dari 5 (lima) komponen, yaitu : a) Hardware (perangkat keras). b) Software (perangkat lunak). c) Procedure. d) Brainware.

\section{Metode Pengumpulan Data}

Teknik pengumpulan data serta bahanbahan penelitian ini dilakukan melalui dua macam penelitian, yaitu; a) Penelitian Lapangan (Field Research), dengan mencari sumber data atau informasi secara langsung ke pusat-pusat informasi sehingga data yang dihasilkan lebih akurat. b) Penelitian Kepustakaan (Library Rasearch), mengumpulkan data dari buku-buku tentang akuntansi pemerintahan dan peraturan perundang-undangan.

\section{Teknik Pengolahan Data}

Untuk mengetahui tingkat signifikasi perbedaan sebelum dan sesudah dilaksanakannya Sistem Akuntansi Keuangan Daerah, maka penelitian menggunakan analisis dan uji hipotesa. Teknik pengolahan data pada penelitian ini akan menggunakan sistem komputerisasi yang dibantu dengan software statistika yakni SPSSversion 16.0, dari beberaa pertanyaan yang diajukan didalam kuesioner untuk menguji hasil hasil penelitian.

\section{HASIL DAN PEMBAHASAN Hasil Penelitian}

Laporan Keuangan Dinas Pendapatan Pengelolaan Keuangan dan Aset Daerah (DPPKAD) Kota Tanjungpinang disusun untuk menyediakan informasiyang relevan mengenai posisi keuangan dan seluruh transaksi yang dilakukan selama satu periode pelaporan.Laporan keuangan digunakan untuk membandingkan realisasi pendapatan dan belanja dengan anggaran yang telah dtetapkan, menilai kondisi keuangan, menilai efektifitas dan efisiensi serta membantu menetukan ketaatannya terhadap peraturan perndangundangan.

\section{Uji Validitas}

Sebelum melaksanakan pengujian terhadap seluruh komponen yang terdapat pada instrument kuesioner, terlebih dajulu akan dilakukan Uji Validitas.

Yang dimaksud dengan validitas adalah pernyataan sampai sejauh mana data yang ditampung pada suatu kuesioner dapat mengukur apa yang ingin diukur. Mengacu pada buku Jemmy Rumengan "Metodelogi Penelitian dengan SPSS" dikatakan Vlid jika r $>0,3$ dan langkah-langkah pengujian validitas dapat dijelaskan sebagai berikut: a) medefnisikn secara operasional suatu konsep yang akan dibuat. b) melakukan uji coba pengukuran tersebut pada jumlah responden. c) mempersiapkan table tabulasi responden. d) menghitung nilai korelasi pada masing-masing pernyataan dengan skor total memakai rumus teknik korelasi product moment, dengan rumus sebagai berikut:$$
\mathbf{r}=\frac{\mathrm{n}\left(\sum X Y\right)-\left(\sum X \sum Y\right)}{\sqrt{\left[n \sum X^{2}\right]\left[n \sum Y^{2}-(Y)^{2}\right]}}
$$

$\mathrm{r}$ : nilai korelasi

$\mathrm{X}$ : skor pertanyaan no.1

$\mathrm{Y}$ : skor total 
$\mathrm{n}$ : jumlah responden

Untuk mengetahui valid tidaknya suatu peeanyaan pada kuesioner maka akan dilakukan perhitungan korelasi antara pernyatan dari setiap nomor dilihat dari 5 (lima) aspek yaitu :Hardware, Software, Procedure, Information, dan Brainware.

Kuesioner yang harus dijawab olh setiap responden memiliki 4 (empat) alternative jawaban. Apabila responden memberi jawaban pada point-point sebagai berikut: a) Point 1, mendapat nilai 1 . b) Point 2, mndapat nilai 2. c) Point 3, mendapat nilai 3. d) Point 4, mendapat nilai 4.

Jawaban yang diberikan oleh responden akan ditotal sesuai dengan jumlah pertanyaan yang berhasil dijawab oleh responden. Daftar nilai jawaban yang diberikan dari masingmasing responden kemudian diolah dengan menggunakan program SPSS version 16.0 untuk mengetahui tingkat validitasnya.

Dari perhitungan uji validitas didapatkan hasil yaitu : a) Untuk aspek Hardware, dari 11 pertanyaan ternyata hanya 6 yang valid sedangkan sisanya tidak valid yaitu sebanyak 5 pertanyaan. b) Untuk aspek Software,dari keseluruhan pertanyaan (5 prtanyaan) dinyatakan valid. c) Untuk aspek Procedure, dari 6 pertanyaan terdapat 4 pertanyaan yang valid dan 2 pertanyaan tidak valid. d) Untuk aspek Information, dari 10 pertanyaan terdapat 6 pertanyaan yang valid dan 4 pertanyaan tidak valid. e) Untuk aspek Brainware, dari 5 pertanyaan terdapat 3 pertanyaan yang vaid dan 2 yang tidak valid.

Hasil yang tidak valid tersebut dapat terjadi kaena pertanyaan yang diberikan tidak dimengerti oleh responden.

\section{Pembahasan}

Kuesioner yang disebarkan dibagi menjadi 5 (lima) komponen penilaian, yaitu :Hardware,

Software, Procedure, nformation, dan Brainwareuntuk melihat efektif atau tidaknya sebuah sistem akuntansi yang dijalankan.

Penjelasan dari masing-masing aspek, dalah sebagai brikut :

a) Hardware, berfungsi untuk input/output (masukan/keluaran) data dan pengolahan serta pemrosesan data internal meliputi computer, komponen-komponen, dan peralatan lain yang berkaitan dengan hal tersebut. Untuk mengetahui efektifitas sistem akuntansi keuangan daerah dar setiap aspek, maka pengolahan data dari hasil jawaban kuesioner adalah sebagai berikut :

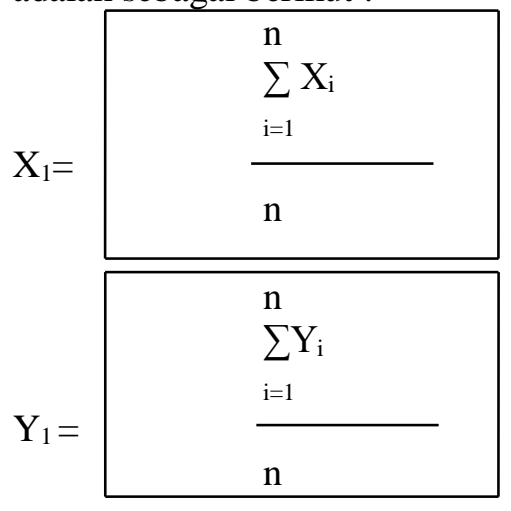

Dimana :

$\mathrm{X}_{1}=$ Penilaian komponen Hardwaresebelum dilaksanakan Sistem Akuntansi Keuangan Daerah.

$\mathrm{Y}_{1}=$ Penilaian komponen Hardware sesudah dilaksanakan Sistem Akuntansi Keuangan Daerah.

$\mathrm{n}=$ Jumlah jawaban yang diberikan responden pada komponen penilaian.

Hasil Hipotesis :

$\mathrm{H}_{\mathrm{o}}=$ Tidak terdapat perbedaan yang signifikan antara komponen Hardwaresebelum dengan setelah pelaksanaan SAKD di DPPKAD Kota Tanjungpinang.

$\mathrm{H}_{\mathrm{a}}=$ Terdapat perbedaan yang signifikan antar komponen Hardware sebelum dengan setelah pelaksanaan SAKD di DPPKAD Kota Tanjungpinang.

b) Software, adalah komponen processing yang berupa program-program dan teknik lainnya untuk mengontrol elemen komuter. Software memberikan instruksi kepada computer. Tahun 2002, DPPKAD Kota Tanjungpinang sudah menggunakan sistem akuntani yang berdasarka komputerisasi. Maka program aplikasi sudah muai dipergunakan sebagai perangkat lunak. perangkat lunak tersebut drasakan sudah cukup membantu.

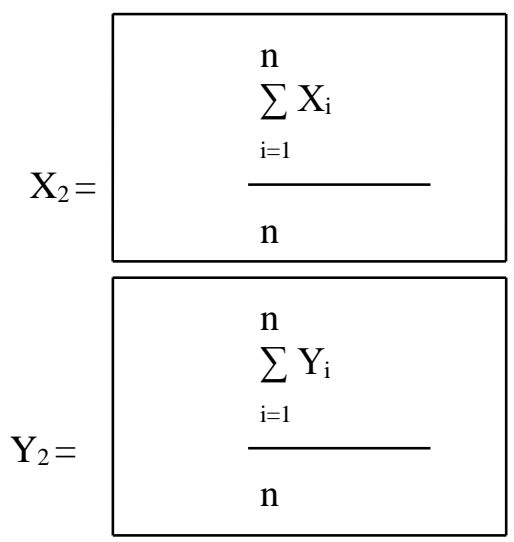


Keterangan :

$\mathrm{X}_{2}=$ Penilaian komponen Software sebelum dilaksanakan Sistem Akuntansi Keuangan Daerah.

$\mathrm{Y}_{2}=$ Penilaian komponen Software sesudah dilaksanakan Sistem Akuntansi Keuangan Daerah.

$\mathrm{n}=$ Jumlah jawaban yang diberikan responden pada komponen penilaian.

Hasil Hipotesis :

$\mathrm{H}_{0}=$ Tidak terdapat perbedaan yang signifikan antara komponen Hardware sebelum dengan setelah pelaksanaan SAKD di DPPKAD Kota Tanjungpinang.

$\mathrm{H}_{\mathrm{a}}=$ Terdapat perbedaan yang signifikan antar komponen Hardware sebelum dengan setelah pelaksanaan SAKD di DPPKAD Kota Tanjungpinang.

c) Procedure, adalah komponen dan suatu urutan kegiatan klerikal yang biasanya melibatkan beberapa orang dalam suatu bagian atau departemen yang dibuat untuk menjamin penanganan secara seragam transaksi yang terjadi berulang.Hasil yang penulis peroleh dari aspek Procedure.

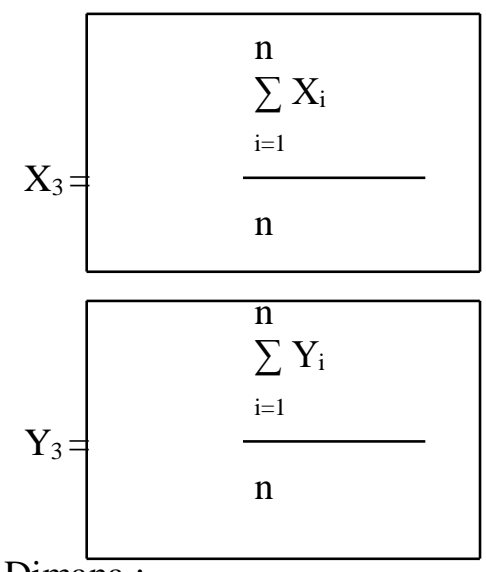

Dimana :

$\mathrm{X}_{3}=$ Penilaian komponen Procedure sebelum dilaksanakan Sistem Akuntansi Keuangan Daerah.

$\mathrm{Y}_{3}=$ Penilaian komponen Procedure sesudah dilaksanakan Sistem Akuntansi Keuangan Daerah.

$\mathrm{n}=$ Jumlah jawaban yang diberikan responden pada komponen penilaian.

Hasil Hipotesis :

$\mathrm{H}_{0}=$ Tidak terdapat perbedaan yang signifikan antara komponen Procedure sebelum dengan setelah pelaksanaan SAKD di DPPKAD Kota Tanjungpinang.

$\mathrm{H}_{\mathrm{a}}=$ Terdapat perbedaan yang signifikan antar komponen Proceure sebelum dengan setelah pelaksanaan SAKD di DPPKAD Kota Tanjungpinang.

d) Information, yaitu hasil dari pengolahan data yang memberikan bentu yang lebih berarti dari suatu kejadian.

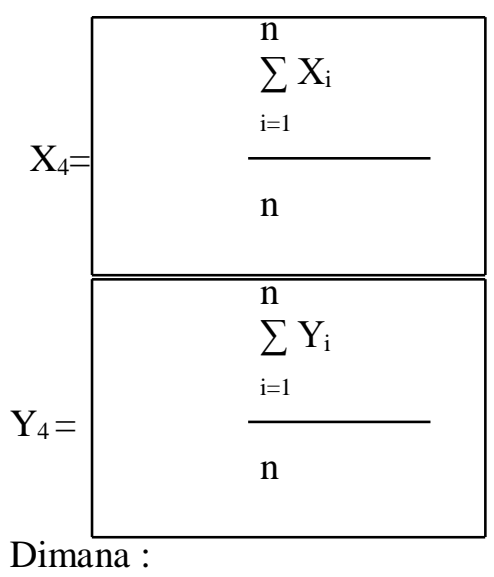

$\mathrm{X}_{4}=$ Penlaian komponen Informationsebelum dilaksanakannya Sistem Akuntansi Keuangan Daerah.

$\mathrm{Y}_{4}=$ Penilaian komponen Information sesudah dilaksanakan Sistem Akuntansi Keuangan Daerah.

$\mathrm{n}=$ Jumlah jawaban yang diberikan responden pada komponen penilaian.

Hasil Hipotesis :

$\mathrm{H}_{0}=$ Tidak terdapat perbedaan yang signifikan antara komponen Information sebelum dengan setelah pelaksanaan SAKD di DPPKAD Kota Tanjungpinang.

$\mathrm{H}_{\mathrm{a}}=$ Terdapat perbedaan yang signifikan antar komponen Information sebelum dengan setelah pelaksanaan SAKD di DPPKAD Kota Tanjungpinang.

e) Brainware, Sumber daya manusia merupakan salah satu unsur yang mendukung terlaksanakannya sistem akuntansi berjalan dengan baik dan lancer. Aspek ini megukur sejauh mana tingkat kesiapan sumber daya manusia pada DPPKAD Kota Tanjungpinang untuk melaksanakan sistem akuntansi yang baru.

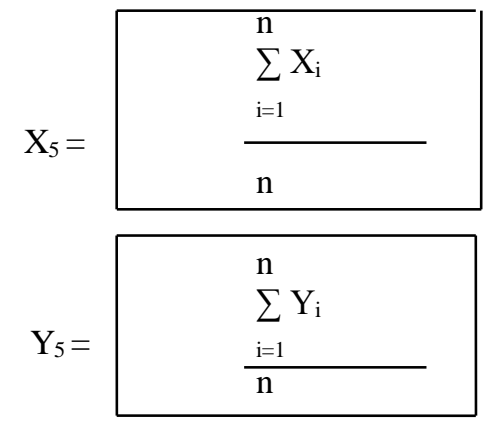


Dimana :

$\mathrm{X}_{5}=$ Penlaian komponen Brainware sebelum dilaksanakannya Sistem Akuntansi Keuangan Daerah.

$\mathrm{Y}_{5}=$ Penilaian komponen Brainware sesudah dilaksanakan Sistem Akuntansi Keuangan Daerah.

$\mathrm{n}=$ Jumlah jawaban yang diberikan responden pada komponen penilaian.

Hasil Hipotesis :

$\mathrm{H}_{0}=$ Tidak terdapat perbedaan yang signifikan antara komponen Brainware sebelum dengan setelah pelaksanaan SAKD di DPPKAD Kota Tanjungpinang.

$\mathrm{H}_{\mathrm{a}}=$ Terdapat perbedaan yang signifikan antar komponen Brainware sebelum dengan setelah pelaksanaan SAKD di DPPKAD Kota Tanjungpinang.

\section{PENUTUP}

\section{Simpulan}

Dari hasil peneltian yang telah dilakukan, dapat ditarik suatu kesimpulan yaitu: a) Dinas Pendapatan dan Pengolahan Keuangan dan Aset Daerah (DPPAKD) Kota Tanjungpinang telah melaksanakan sistem akuntansi yang baru Sistem Akuntansi Keuangan Daerah dengan sistem komputerisasi yng terdiri dari 5 (lima) aspek, yaitu Hardware, Softwre, Procedure, Informtion dan Brainware. b) Basis akuntansi yang digunakan dalam Sistem Akuntansi Keuangan Daerah DPPKAD Kota Tanjungpinang untuk pengakuan pendapatan, belanja dan pembiayaan dalam Laporan Realisasi Anggaran dan Laporan Aliran Kas digunakan Basis Kas yang berarti bahwa pendapatan dan penerimaan pembiayaan diakui pada saat kas diterima oleh daerah.

\section{Saran}

Ada beberapa saran yang dapat disampaikan untuk perbaikan pelaksanaan Sistem Akuntansi Keuangan Daerah pada DPPKAD Kota Tanjungpinang sebagai bahan masukanuntuk kedepannya, yaitu; a) Masih diperlukan penyesuain yang mendalam tentang penggunaan sistem komputerisasi, baik dalam hal aplikasi maupun opersinya, selain itu SDM yang ada masih kurang dan sangat minim untuk menjalankan aplikasi tersebut b) Jaringan kerja (network) untuk penyusunan dan pemeriksaan laporan keungan harusnya dapat menjangkaukeseluruhan bidang, bukan hanya bidang tertentu saja. c) Sebainya selalu diadakan pelatiha secara rutin mengenai sistem akuntansi khususnya mengenai sistem yang terkomputerisasi, sehingga laporan keuangan pemerintah yang dihasilkan lebih relevan, andal, dn dapat dibandngkan serta mudah dipahami.

\section{DAFTAR PUSTAKA}

Husaini Usman, R.Purnomo Setiady Akbar, 2006. Pengantar Statistika. Bumi Aksara, Jakarta.

Hasan, Iqbal, 2004. Analisis Data Penelitian dengan Statistika, PT. Bumi Aksara, Jakarta.

Hasan, Iqbal, 2001. Pokok-pokok Materi Statistika 2 (Statistika Informatif), PT. Bumi Aksara, Jakarta

Rumengan, Jemmy, 2010. Metodelogi Penelitian dengan SPSS, Uniba Press, Batam.

Halim, Abdul, 2001. Akuntansi Keuangan Daerah, Salemba Empat, Jakarta.

Indra Bastian, 2003. Sistem Akuntansi Sektor Publik - Konsep untuk Pemerintahan, Edisi Kedelapan, PT. Gramedia Pustaka Utama, Jakarta.

Mardiasmo, 2002. Akuntansi Sektor Publik, Penerbit Andi, Yogyakarta.

Bodnar, Geroge H, dan Hopwood, William S, 2003. Sistem Informasi Akuntansi, Edisi Keempat, Salemba Empat, Jakarta.

Renyowijoyo, Muindo, 2008. Akuntansi Sektor Publik Organisasi Non Laba, Mitra Wacana Media, Jakarta.

Sugiyaono, 2007. Metode Penelitin Bisnis, Alfabeta, Bandung.

Bastian, Indra 2008. Telaah Kriis Standar Pemeriksaan Keuangan Negara, BPFE Yogyakarta.

Nondiawan, Deddi, Sondi Putra, Iswahyudi, dan Rahmawati, Maulidah, 2007. Akuntansi Pemerintahan, Salemba Empat, Jakarta. 